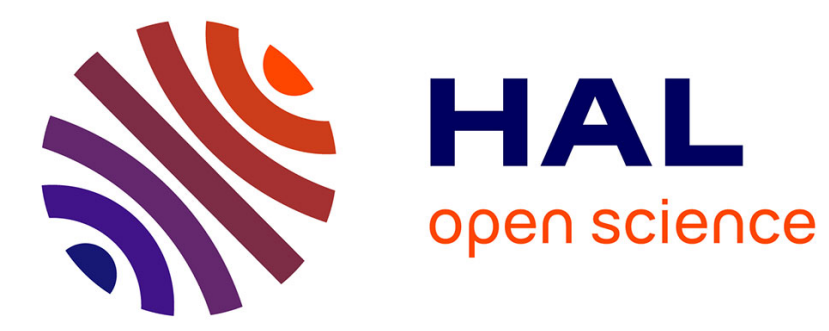

\title{
MOBILITY OF SODIUM ON THE (110) FACE OF TUNGSTEN
}

\author{
R. Morin
}

\section{To cite this version:}

R. Morin. MOBILITY OF SODIUM ON THE (110) FACE OF TUNGSTEN. Journal de Physique Colloques, 1984, 45 (C9), pp.C9-17-C9-21. 10.1051/jphyscol:1984904 . jpa-00224380

\section{HAL Id: jpa-00224380 https://hal.science/jpa-00224380}

Submitted on 1 Jan 1984

HAL is a multi-disciplinary open access archive for the deposit and dissemination of scientific research documents, whether they are published or not. The documents may come from teaching and research institutions in France or abroad, or from public or private research centers.
L'archive ouverte pluridisciplinaire HAL, est destinée au dépôt et à la diffusion de documents scientifiques de niveau recherche, publiés ou non, émanant des établissements d'enseignement et de recherche français ou étrangers, des laboratoires publics ou privés. 


\title{
MOBILITY OF SODIUM ON THE (110) FACE OF TUNGSTEN
}

\author{
R. Morin
}

CRMC2-CNRS, Campus de Luminy, Case 913, 13288 Marseille Cedex 09, France

\begin{abstract}
Résumé - La mobilitẻ et la compressibilité du sodium adsorbé sur la face (110) du tungstène sont dẻterminées par la mesure de la fonction de corrélation temporelle des fluctuations du courant local d'émission de champ pour des recouvrements en sodium variant de $2 \times 10^{13}$ à $3 \times 10^{14}$ atomes par $\mathrm{cm}^{2}$ et des températures de 170 à $500 \mathrm{~K}$. Deux régimes de température apparaissent clairement séparant des phases où les paramètres de diffusion sont complètement différents. Par comparaison avec les résultats obtenus par diffraction d'êlectrons lents la transition entre les deux régimes apparait comme une transition continue ordre loca1-désordre.
\end{abstract}

Abstract - The mobility and the compressibility of sodium adsorbed on the (110) face of tungsten have been determined by measuring the time correlation function of the local field emission current fluctuations for coverages from $2 \times 10^{13}$ to $3 \times 10^{14}$ atoms $\mathrm{cm}^{-2}$ and for temperatures from 170 to 500K. Two temperature regimes clearly appear dividing phases where the diffusion parameters are complete1y different. By comparison with slow electron diffraction results the transition between both regimes appears as a continuous local-order-disorder transition.

The introduction of the field-emission-fluctuation method to investigate the mobility and the compressibility of adsorbates $|1,2|$ has recently given very interesting results concerning gas on metal systems $|3,4,5,6|$. The improvement compared with classical spreading methods is based upon the fact that it is a microscopic method directly giving the diffusion coefficient D (through the correlation time $\tau$ of density fluctuations and the probed region area $A$ ) and the compressibility $X$ (through the relative density fluctuation amplitude) of the adphase versus the mean coverage on a given face without detailed analysis of a concentration profile. In this short paper, using this method; we present the results obtained in one case (Na on W(110)) belonging to an other class of adsorption system i.e. metal on metal system. One interest in studying this system comes from the knowledge of the adsorption bond characteristics (i.e. ionic type) and of the phase diagram obtained by slow electron diffraction $|7,8|$.

A classical stainless steel field emission microscope has been used, allowing an ultimate ultra-high vacuum of 1 to $3 \times 10^{-11}$ Torr. Local current measurements are achieved using a probe-hole technique with a tip holder movable on bellows. The temperature of the tip can be changed by classical servo-loop-current from $80 \mathrm{~K}$ to $3000 \mathrm{~K}$. The evaporation source is an alkali metal dispenser furnished by S.A.E.S. Getter which is usually used in the phototube industry. It is a container filled up with sodium chromate and a non evaporable agent $\mathrm{Zr} 16 \%$ - A1 alloy named St 101 to prevent from gas evaporation when heating the source.

Local current correlation functions are measured in a similar way as that used by Di Foggio and Gomer to study the diffusion of hydrogen on W(110) (Fig. 1) The fowler-Nordheim parameters $|9|$ governing the local field emission current $i$ have been measured using a linear regression program on $\log \left(i / V^{2}\right.$ ) $v s V^{-1}$ where $V$ is applied tip voltage. Fig. 2 shows variations of these parameters with $\mathrm{Na}$ coverage which is obtained from work function versus coverage measurements on a macroscopic crystal $|8|$. 


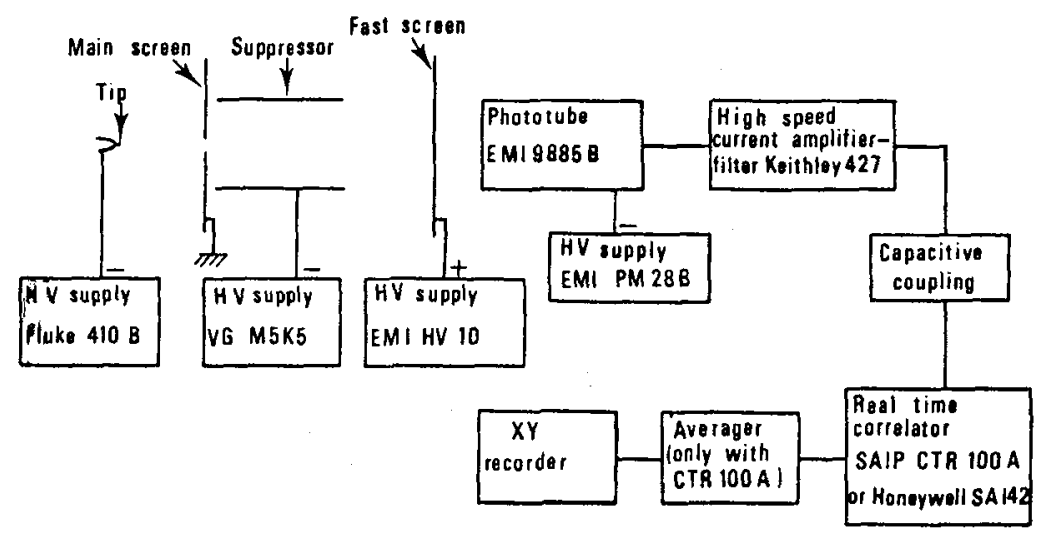

Fig. 1 - Block diagram of the electrical arrangement

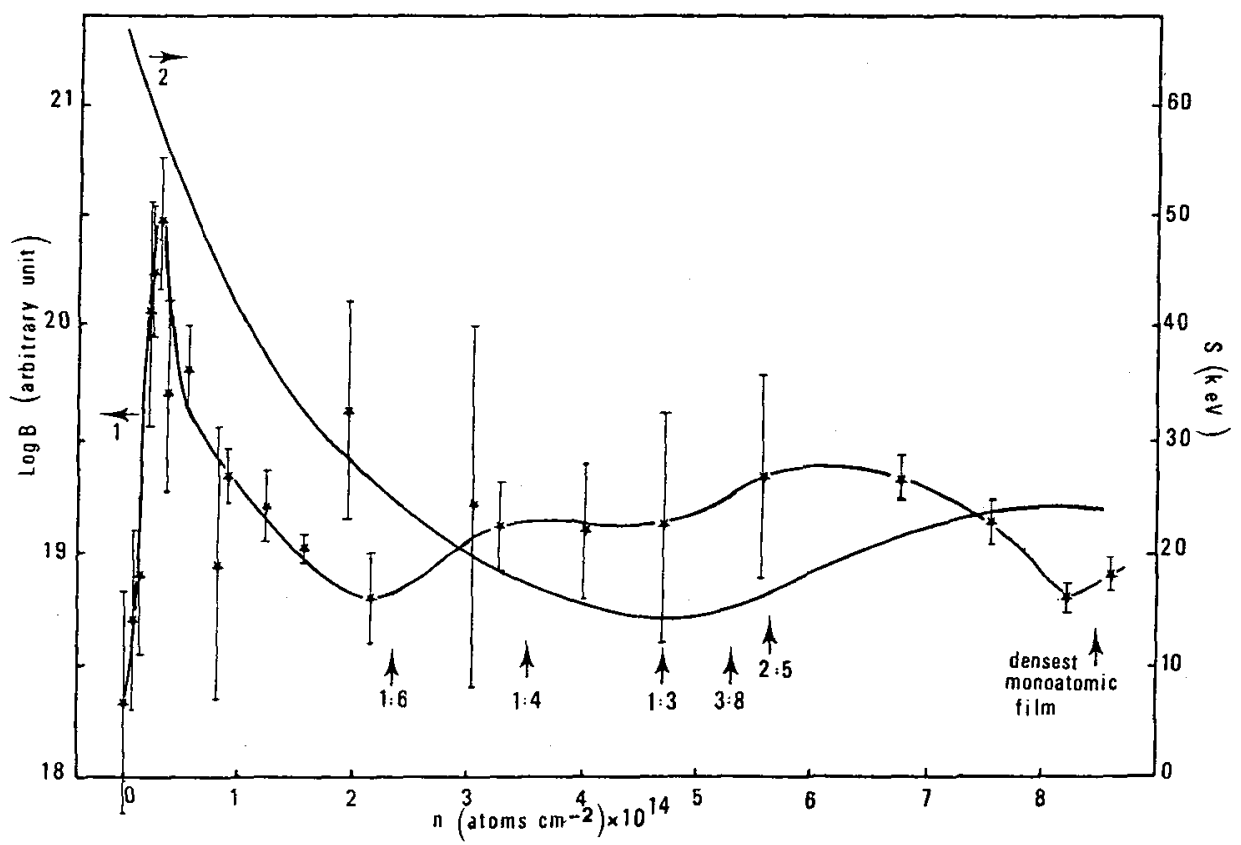

Fig. 2 - Preexponential Log $B$ (curve 1) and slope $S$ (curve 2) of Fowler-Nordheim plots versus coverage (stochiometries for observed slow electron diffraction structures are indicated by arrows).

Correlation functions have been measured for coverages from 0.2 to $3 \times 10^{14}$ atoms $\mathrm{cm}^{-2}$ and for temperatures from $\sim 170$ to $500 \mathrm{~K}$. The long time behaviour exhibits a slower decay $\left(\tau^{-0.7}\right)$ than that $\left(\tau^{-1}\right)$ predicted by the simplest theoretical models $|1,2|$. 
Fig. 3 shows a plot of D vs $T$ in Arrhenius scales for different coverages.

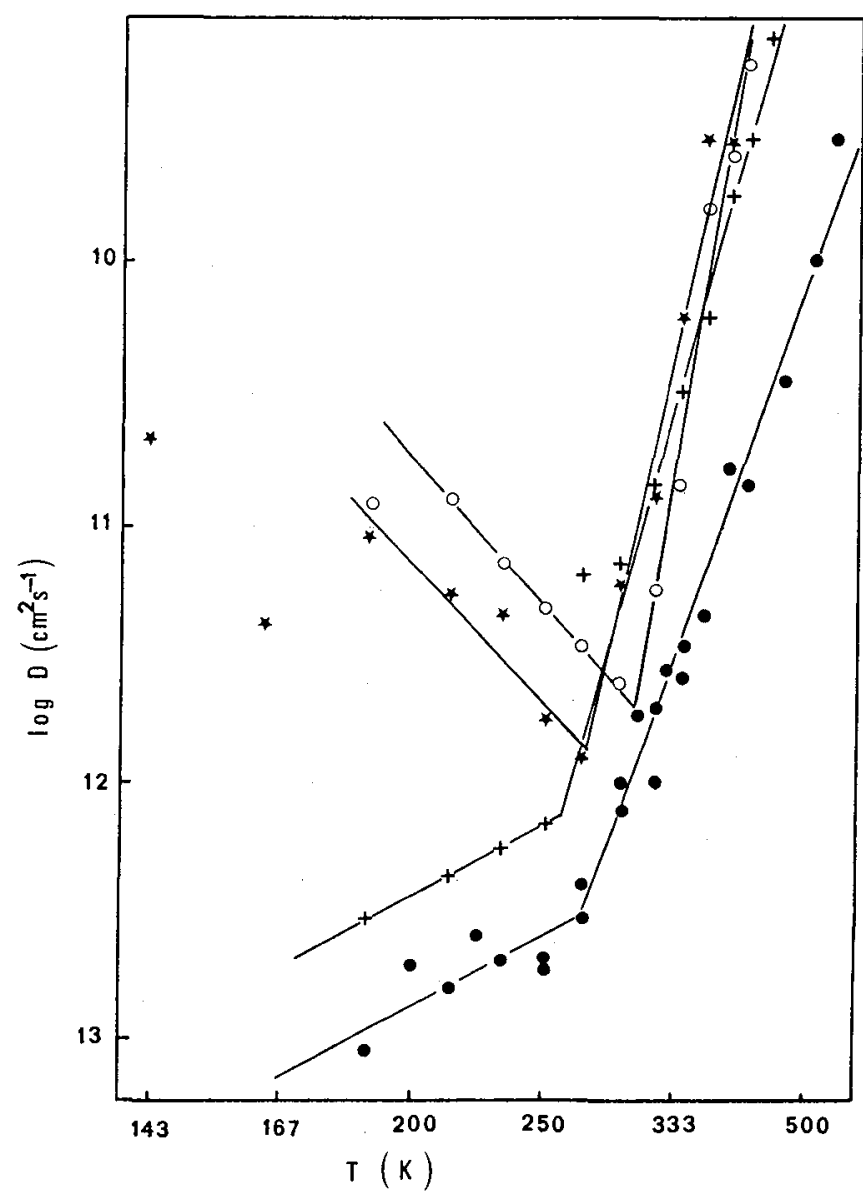

Fig. 3 - Diffusion coefficient versus temperature and coverage $\left((\bullet): \mathrm{n}=2 \times 10^{13}\right.$ at $\cdot \mathrm{cm}^{-2}$; (+) $: \mathrm{n}=1.25 \times 10^{14} \mathrm{at} . \mathrm{cm}^{-2}$; (o) $: \mathrm{n}=2.3 \times 10^{14}$ at. $\mathrm{cm}^{-2}$; (4) $: \mathrm{n}=3 \times 10^{14}$ at. $\left.\mathrm{cm}^{-2}\right)$

As can be clearly seen in Fig. 3 two temperature regimes appear, characterized by changes of Log D vs 1/T parameters. Arrhenius fits of these curves give the relevant parameters values indicated in table 1 assuming $D=D_{0} \exp (-E / k T)$.

\begin{tabular}{|c|c|c|c|c|c|}
\hline \multicolumn{2}{|c|}{ coverage $\left(\times 10^{14}\right.$ atoms $\left.\mathrm{cm}^{-2}\right)$} & .2 & 1.25 & 2.3 & 3 \\
\hline \multirow{2}{*}{$\begin{array}{l}\text { High temperature } \\
\text { regime }\end{array}$} & $\log D_{0}\left(\mathrm{~cm}^{2} \mathrm{~s}^{-1}\right)$ & $-7.6 \pm 0.5$ & $-5.4+0.5$ & $-2 \cdot 2 \pm 1.4$ & $-3.85 \pm 1.2$ \\
\hline & $\mathrm{E}(\mathrm{eV})$ & $0.27 \pm 0.03$ & $0.35+0.03$ & $0.58 \pm 0.1$ & $0.44 \pm .07$ \\
\hline \multicolumn{2}{|c|}{ Transition temperature (K) } & $267 \pm 15$ & $260 \pm 5$ & $305 \pm 5$ & $275 \pm 7$ \\
\hline \multirow{2}{*}{$\begin{array}{l}\text { Low temperature } \\
\text { regime }\end{array}$} & $\log D_{0}\left(\mathrm{~cm}^{2} \mathrm{~s}^{-1}\right)$ & $-11.9 \pm 0.5$ & $-11.5 \pm 0.02$ & $-14 \pm 0.1$ & $-14.2 \pm 0.5$ \\
\hline & $\mathrm{E}(\mathrm{eV})$ & $0.055 \pm 0.02$ & $0.053 \pm .001$ & $-1.07 \pm .04$ & $-1 \pm .2$ \\
\hline
\end{tabular}

Table 1 - Diffusion parameters in both temperature regimes and transition temperature between these regimes. 
The diffusion parameters appear quite normal in the high temperature regime although the increase of $D_{0}$ with coverage already observed for oxygen and hydrogen on $W(110)$ by Gomer and coworkers always stays an open question $|10,11|$. The numerical values of $D_{0}$ as well as the temperature dependance in the low temperature regime clearly indicate that the single adatom jump picture is a poor picture to describe the system.

The dependance of the relative fluctuation amplitude $\left\langle\delta n^{2}\right\rangle /\langle n\rangle$ (which is proportional to the product of the compressibility times coverage and temperature) vs coverage $\mathrm{n}$ and temperature $\mathrm{T}$ is shown in $\mathrm{Fig}$. 4 .

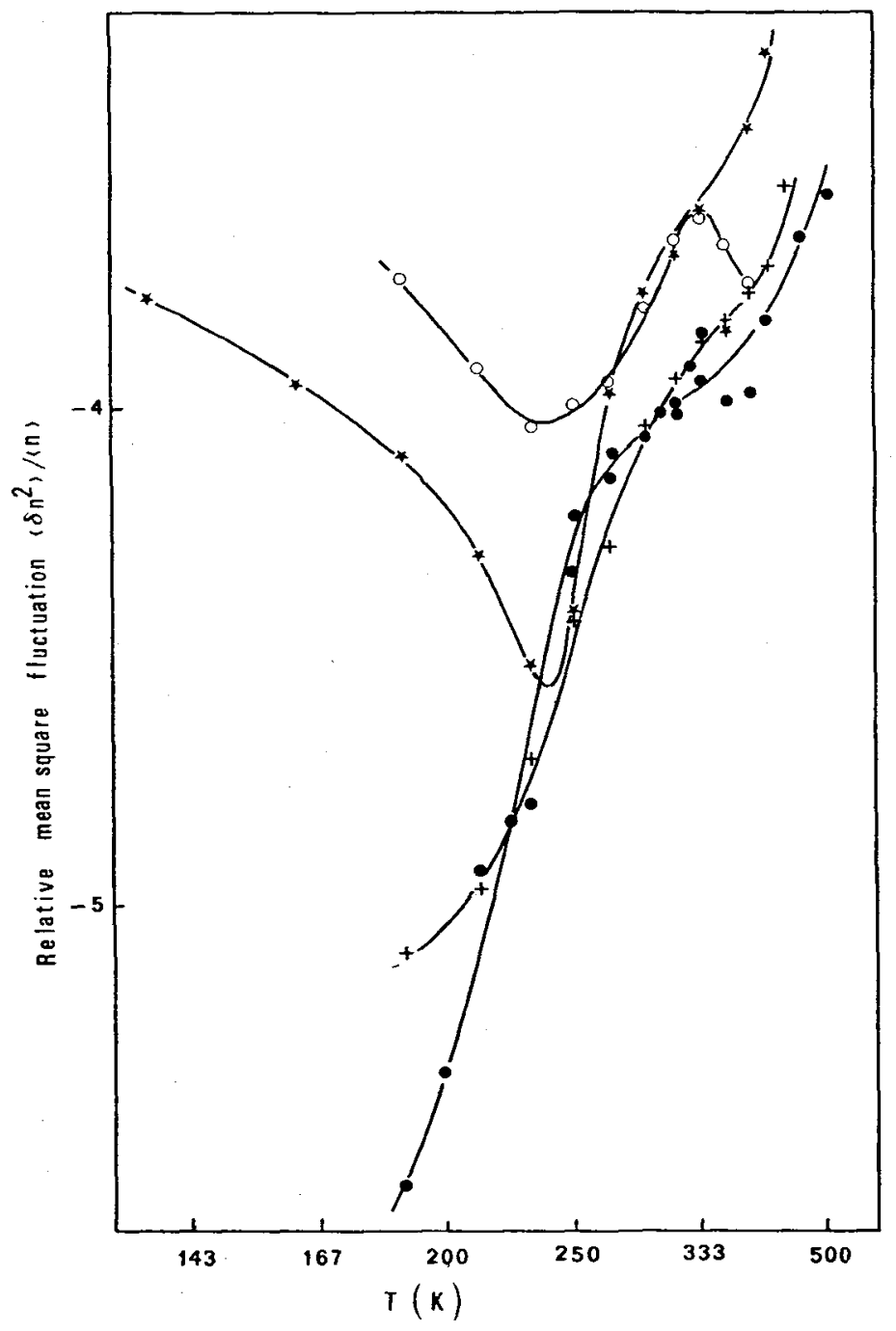

Fig. 4 - Variations of the relative mean square fluctuation amplitude $\left\langle\delta n^{2}\right\rangle /\langle n\rangle$

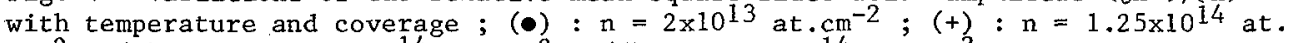
$\mathrm{cm}^{-2} ;(0): \mathrm{n}=2.3 \times 10^{14} \mathrm{at} . \mathrm{cm}^{-2} ;(*): \mathrm{n}=3 \times 10^{14} \mathrm{at}^{\prime} \mathrm{cm}^{-2}$. 
The transition temperature observed in diffusion corresponds to an inflexion point from positive to negative curvature on the $\left\langle\delta n^{2}\right\rangle /\langle n\rangle$ vs $T$ curve. The increase of $\left\langle\delta n^{2}\right\rangle /\langle n\rangle$ with temperature in the high temperature regime indicates an effective repulsive interaction $|12|$ between adatoms (whereas this characteristic is only preserved for high coverages in the low temperature regime).

One interesting point can be underlined concerning some characteristics of the transition. Firstly because of the continuity of the diffusion coefficient the transition is continuous. Then a useful comparison is possible with slow-electron diffraction results $|8|$ where order-disorder transitions are observed for such coverages at low temperatures. These transitions are indicated by steep decreases of diffraction spot intensity with temperature which are followed by high temperature tails indicative of short-range-order persistence. Although, using this technique, no quantitative analysis can be obtained the tails of these curves go to zero for temperatures between 250 and $300 \mathrm{~K}$ which is in the range where we find our diffusion transition temperature so that the identification of both transitions appears natural. The scale on which order is distroyed can be precised as being smaller than the probed region size ( $\sim 50 \AA$ ) because the correlation function is the same in both temperature regimes. The transition we observe in diffusion then probably corresponds to a continuous short-range-order-disorder transition.

\section{REFERENCES}

II GOMER, R., Surf. Sci. 38. (1973) 373

12| MAZENKO, G., BANAVAR, J.R. and GOMER, R., Surf. Sci. 107 (1981) 459

13! CHEN, J.R. and GOMER, R., Surf. Sci. 79 (1979) 413

I4I CHEN, J.R. and GOMER, R., Surf. Sci. $\overline{81}$ (1979) 589

151 CHEN, J.R. and GOMER, R., Surf. Sci. $\overline{94}$ (1980) 456

161 DI FOGGIO, R., and GOMER, R., Phys. Rev. B 25 (1982) 3490

17| KLIMENKO, E.V., and NAUMOVETS, A.G., Surf. Sci. 14 (1969) 141

181 MEDVEDEV, V.K., NAUMOVETS, A.G., and FEDORUS, A.G., Soviet Phys. - Solid State$12(1970) 301$

|9| GOMER, R., Field Emission and Field Ionization (Harvard University Press, Cambridge, Mass, 1961)

| $1.0 \mid$ BANAVAR, J.R., COHEN, M.H., and GOMER, R., Surf. Sci. 107 (1981) 113

$111 \mid$ VEDULA, Yu.S., LYUKSYUTOV, I.F., NAUMOVETS, A.G., and POPLAVSKII,V.V., Pis 'ma Zh. Eksp. Teor. Fiz. 36, $\mathbf{N}^{\circ}$ 3, (1982) 73

|12| BELL, B., GOMER, R., and REISS, H., Surf. Sci. 55 (1976) 494 